\title{
National Diet and Nutrition Survey: fat and fatty acid intakes from the first year of the rolling programme
}

\author{
G. K. Pot ${ }^{1}$, C. J. Prynne ${ }^{1}$, C. Roberts ${ }^{2}$, B. Teucher ${ }^{1}$, E. Fitt ${ }^{1}$, D. Cole ${ }^{1}$, B. Bates ${ }^{2}$, H. Henderson ${ }^{2}$, \\ S. Pigott ${ }^{2}$, C. Deverill ${ }^{2}$, G. Swan ${ }^{3}$ and A. M. Stephen ${ }^{1}$ \\ ${ }^{1}$ MRC Human Nutrition Research, Elsie Widdowson Laboratory, Cambridge CB1 9NL, UK, ${ }^{2}$ National Centre for Social \\ Research, London ECIV OAX, UK and ${ }^{3}$ Food Standards Agency, 6B Aviation House, 125 Kingsway, \\ London WC2B 6NH, UK
}

High fat intakes are an established risk factor for several chronic diseases, such as CVD. In the UK, the Department of Health recommends a maximum intake from total fat of $35 \%$, SFA of $11 \%$, PUFA of $6.5 \%$ and trans fat of $2 \%$ of daily food energy intake ${ }^{(1)}$. We report the dietary intakes and main food sources of these nutrients from the first year of the National Diet and Nutrition Survey (NDNS) rolling programme, from dietary intake data collected between February 2008 and June $2009^{(2)}$, covering the age range 1.5 years and above. Dietary data were collected in the form of a 4-d estimated food diary, including both weekend days; nutrient intakes were calculated using the dietary assessment system developed at MRC Human Nutrition Research, DINO (Data In Nutrients Out), using the Nutrient Databank of the Food Standards Agency. Results were compared with the Dietary Reference Values (DRV) for the UK ${ }^{(1)}$ and with dietary intake data from the NDNS of Young People (4-18 years) carried out in $1997^{(3)}$ and of adults (19-64 years), carried out in $2000-01^{(4)}$. The 7-d intake data from these surveys have been recalculated for $4 \mathrm{~d}$ to allow direct comparisons.

Results showed that total fat provided $34-36 \%$ of food energy across all age groups. Intakes were very similar to the previous survey for adults but lower than previous surveys for children. The mean intake for adult women, boys (4-18 years) and younger girls (4-10 years) met the DRV, while mean intake for adult men and older girls (11-18 years) was just above the DRV. The major contributors to total fat intake were meat and meat products, milk and milk products and cereals and cereal products. SFA intakes were lower compared with previous surveys, ranging from 12.8 to $15 \%$ of food energy, but were still above the DRV. Meat and meat products, cereal and cereal products, milk and milk products, especially cheese, were the major contributors to SFA intake. The mean intakes of MUFA were $12.5 \%$ food energy for adults and children aged 4-18 years and $11.2 \%$ for toddlers and all intakes were below the DRV. Compared with previous survey data, MUFA intake showed slight increases in absolute intakes and as percentage food energy for all groups, which are likely due to the increases in meat consumption. The intake of $n$-6 PUFA ranged from $3.9 \%$ food energy for toddlers to $5.3 \%$ for adult women. Compared with previous survey data, intake of $n$-6 PUFA was little changed, although the direction of change was downwards for all age groups for both absolute intakes as percentages food energy. The intake of $n-3$ PUFA represented 0.7 to $1.1 \%$ food energy. Compared with previous survey data, the direction of change for $n-3$ PUFA was upwards for all age groups, although the differences in absolute terms were very small. Trans fatty acids intakes were lower than in previous NDNS and were less than 2 g/d for all age groups, representing $0.8 \%$ of food energy and met the DRV in all age groups. The level of trans fatty acids from industrial sources have been reduced in recent years, resulting in higher proportion coming from natural sources, such as meat and dairy products.

Dietary intake of fat and fatty acids are moving in a direction towards recommended levels for the UK population. However, there remains considerable room for further improvement.

1. Department of Health (1991) Dietary Reference Values for Food Energy and Nutrients for the United Kingdom. Report on Health and Social Subjects No 41. London: HMSO.

2. Bates B, Lennox A \& Swan G. NDNS Headline results from Year 1 of the Rolling Programme. Available online at http://www.food.gov.uk/multimedia/ pdfs/publication/ndns0809appendixk.pdf (accessed 1 March 2010).

3. Gregory JR, Lowe S, Bates CJ et al. (2000). National Diet and Nutrition Survey: Young People Aged 4 to 18 Years. Volume 1: Report of the Diet and Nutrition Survey. London: TSO.

4. Henderson L, Gregory J \& Swan G (2002) National Diet and Nutrition Survey: Adults Aged 19 to 64 Years. Volume 2: Energy, Protein, Carbohydrate, Fat and Alcohol Intake. London: TSO. 